\title{
Mala siembra de Rafael Rubio
}

Valparaíso, Universidad de Valparaíso, 2013, 171 pp.

\section{Claudio Guerrero Valenzuela}

Pontificia Universidad Católica de Valparaíso. Valparaíso, Chile.

cmguerre@uc.cl

Z ste libro, el quinto del autor, inaugura la colección de poesía del nuevo sello editorial que la Universidad de Valparaíso ha decidido dar a luz bajo la dirección de Cristián Warnken. Se trata de una cuidada edición que contempla tapa dura a color y encuadernación con costura a la vista con hilo de color rojo, y que explicita la artesanía del objeto en tanto configuración de un proceso de producción no seriada que busca rescatar la unicidad y particularidad del libro, en tiempos en que el libro como bien cultural ha perdido valor de uso y ha cristalizado como valor de cambio, en desmedro de los bienes simbólicos que pone en entredicho. Llama la atención, eso sí, que como sello regional, descentrado, haya escogido a un autor para inaugurar su colección que escasos vínculos tiene con el puerto.

Hasta la publicación de Mala siembra, Rafael Rubio (Premio Pablo Neruda 2008) ha publicado cuatro poemarios, a saber: Arbolando (Santiago, Ediciones DIBAM, 1998), Madrugador tardío (Santiago, Ediciones del Temple, 2000), Luz rabiosa (Los Angeles, Camino del Ciego Ediciones, 2007) y Caudal (Santiago, Editorial Pfeiffer, 2010). Todos estos textos, sin excepción, se comunican entre sí y han ido delineando las reconocidas líneas de trabajo que este autor ha venido explotando de manera sistemáticamente coherente, bajo una esmerada producción que respeta la articulación más tradicional del verso, la musicalidad y el ritmo como formas contenedoras de sus temáticas recurrentes: la muerte del padre, la trascendente religiosidad y la reflexión sobre el arte poético.

Mala siembra está compuesto de un elogioso prólogo del poeta peruano Carlos Germán Belli, Premio Pablo Neruda 2006, y ocho secciones: La queja (un solo poema), Destierro (13 poemas), La familia (15 poemas), La ruina (18 poemas), Los discursos (6 poemas), Las frondas (7 poemas), Los esposos (7 poemas) y La Iglesia (7 poemas). Cada una de estas secciones se concentra en torno a un eje temático que da la sensación de conjunto, de entramado arquitectónico que muestra las vigas de su estructura, dejando al descubierto el arte de la composición poética en su compleja trama. 
En el único poema que conforma la sección La queja y que funciona como introducción al conjunto, el hablante expresa: “Señor, cómo nos zumba la miseria! (...) ¿Solo para los muertos es la tierra?” (15). El tono es evidentemente quejumbroso, pero prontamente el sujeto se encarga de plantear el cambio de tono poniendo sobre la mesa las cartas del desafío: "Dale muerte a la yegua, si eres fiero. / Dale muerte al caballo, si eres gallo. / ¡Y que después del rayo, zumbe el trueno!” (15). Con esto, se evidencia el escenario propuesto para todo el poemario: la idea de que el proceso de escritura es un campo de disputa, un torneo de esos por quien canta (paya) mejor, una lucha encarnizada por proponer una voz que sobresalga sobre el resto, que supere al otro, situación por cierto que requiere de maestría, gallardía y manejo de los códigos propios del arte; habilidades que el poeta se encarga de dejar bien en claro, a cada rato, que maneja y que las maneja bien. No por nada gran parte de los poemas que conforman este libro tienen este carácter confrontacional hacia un otro que incluso adquiere nombre, características y cuerpo y que bien puede ser el propio fantasma improductivo del poeta que a veces lo asedia: “¿Ves, Títiro?, comprende de una vez / que el verso libre no te va ni luce” (111). Esto supondría una oposición entre una buena siembra (una buena manera de hacer poesía) versus una mala siembra (una mala manera de hacer poesía), en tiempos como los actuales, "como es habitual en estos pobres / días, en los que el arte del poema / se ha reducido al epitafio, Títiro" (110). Tiempo de miseria, señala este hablante defensor de la métrica, que hace que las liras que se componen hoy en día bien merecerían "un gargajo de San Juan" (117).

Se trata, por cierto, de un debate que se viene produciendo desde hace unos años en algunos aislados espacios de prensa y especialmente en sitios electrónicos especializados en poesía chilena y del cual Rubio forma parte como uno de sus protagonistas: una suerte de querella entre clásicos y modernos, tradicionalistas y vanguardistas, poetas con oficio y escribientes sin manejo de la métrica, quevedistas y gongoristas del siglo XXI. Más allá de las anecdóticas descalificaciones mutuas que aquí no nos interesan, el debate plantea un tema no menor: qué tipo de poesía se está escribiendo en nuestro país, cómo se encuadra en el marco de una vasta tradición poética y cómo valora la crítica una producción y otra. El hecho de que las aguas estén divididas expresa, tal vez, que el panorama es más bien confuso y probablemente dé cuenta de una aporía que solo la distancia histórica podrá zanjar. Lo que sí me parece interesante rescatar aquí es más bien lo banal y mezquino de la discusión por tratar de obtener el trofeo que te califique como $e l$ poeta representativo de tu generación, por lo que considero que ocupar esfuerzos 
en ello es una tarea desgastantemente inútil. En este sentido, parece mucho más relevante dar cuenta de las problemáticas y tensiones de estas poéticas sin entrar en descalificar a priori en nombre de una verdad con mayúscula las formas de sus lenguajes, y en concreto hay aquí algunas cosas interesantes que pone en circulación esta poesía de Rafael Rubio.

En cada una de las secciones que conforma el poemario el hablante despliega la semántica propuesta en el poema inicial. Es así como en la sección Destierro, se repiten de manera isotópica y aliterada términos que van cargando de sentido la lectura: la miseria, la muerte, el hambre, la ruina, la pobreza, el cuerpo, la siembra, el rayo, etc. Los sonidos de estos poemas remiten -recurriendo a las constantes alusiones campestres del poemario- a una suerte de balido murmullante, un zumbido de abeja, significantes que se conectan con ese imperativo del poema inicial: "que zumbe el trueno". Porque a la larga, la poesía de Rubio es justamente eso: el zumbido del trueno tras el relámpago de la escritura. En su lógica, la mala siembra sería únicamente el relámpago (que deja con hambre) y la buena siembra el relámpago más el trueno, es decir, la imagen y el sonido: un constructo complejo que "busca en la lumbre el enjambre, / punza en la sombra la lumbre" (33). Luz rabiosa y sonora que se apropia no solo de formas clásicas sino que también de grandes proyectos vanguardistas históricos.

Dijimos también que otra de las temáticas recurrentes de esta poesía guarda relación con los diálogos familiares con los antepasados poéticos: el abuelo y el padre muertos, Alberto y Armando, algo que se hace presente con mayor fuerza en la sección La familia, en donde se incluye para cada uno una elegía, siendo mucho más extensa (y más propiamente elegíaca), la dedicada al padre: "¿Estabas ahi cuando te pusieron / en tu tumba? ¡Dime, padre!" (55, la cursiva es del original). Esta temática es una constante que atraviesa los intereses de creación del autor y resulta sorprendente las posibilidades de reinvención que no agotan los recursos ni los procedimientos para referirse a estos antepasados que como fantasmas asedian y rondan la mano que escribe sobre el papel.

En este poemario también es posible encontrar una veta muy explorada en producciones anteriores y que tiene que ver con cierto escepticismo religioso: "La noche será larga como la muerte de Dios" (97); algunas dudas existenciales trascendentes: “¿la vida es una, y múltiple la muerte?” (97) y críticas a la institución eclesiástica, como en el poema dedicado "a Karadima y sus cuervos": "Vienen diez curas buscando niños. / Diez curas negros que tienen hambre" (23). La progresión sustantiva y adjetiva va acrecentando e intensificando la visión que se tiene de estos cazadores de niños: diez curas 
negros, diez avideces, diez perros negros que buscan diez "tiernos / niños proclives a su mordida" (23). Se trata de un poema contingente, que por lo mismo resalta a la vista, escapando de algún modo a la lógica del conjunto. Estos versos dan cuenta de una preocupación moral que atañe al sujeto en gran parte de su producción poética: la pregunta por el sentido con un carácter que recoge la tradición lírica de algunas poéticas que enfrentan la existencia de Dios y las dudas ante la verdadera y genuina acción relevante, para la vida, de la institución eclesiástica y de quienes forman parte de sus votos.

En conclusión, este poemario viene a ser una muestra de trabajo meticuloso con la palabra para tanta poesía que se escribe hoy en día a la carrera, con un apresuramiento inoficioso que no deja más que al descubierto, a la larga, un desprecio por el trabajo poético. El rigor en la construcción del verso, en la mantención de regularidades rítmicas y el imbricado juego sonoro de sus formas sin dejar de lado profundas problemáticas de contenido, hacen de su lectura una experiencia sensorial con la que da gusto encontrarse hoy en día, en tiempos de carencias estéticas. 